\title{
Use of Topical Hemostatic Agents during Liver Resection
}

\author{
Frederik Berrevoet Bernard de Hemptinne \\ Department of General Surgery, Division of Hepatobiliary Surgery and Liver Transplantation Service, \\ Ghent University Hospital Medical School, Ghent, Belgium
}

\section{Key Words}

Topical hemostatic agents - Liver resection • Fibrin sealants • Hepatic resection

\begin{abstract}
Despite all recent developments in surgical techniques during liver surgery, blood loss is still one of the main causes for postoperative morbidity and mortality. Other complications include bile leakage and fluid accumulation intraperitoneally. Fibrin sealants are able not only to enhance clot formation and wound healing but possibly work as a sealing device for postoperative leakage and fistula formation. In this overview the underlying mechanisms for these agents are discussed and several clinical data concerning liver surgery will be reported.

Copyright $\odot 2007$ S. Karger AG, Base
\end{abstract}

\section{Introduction}

Advances in surgical technique have reduced the occurrence of postoperative complications following liver resection [1]. Despite these improvements, hepatic resection might still be associated with considerable intraoperative blood loss. The predisposition of this organ to diffuse bleeding is directly related to its extreme vascularity, particularly because of the hepatic sinusoidal structure, which does not have smooth muscle capable of contraction to induce vasoconstriction [2]. Consequently, traumatic damage, including parenchymal lacerations and fractures, and surgical cutting during elective operative procedures tend to expose wide, raw surfaces with multiple bleeding sites that are often not amenable to suturing and ligation [3].

Although there is almost total agreement on issues such as the need for bloodless dissection to achieve favorable results, several authors have still reported relatively high rates of patients receiving blood transfusions undergoing partial hepatectomy recently. On the contrary, there are also large series in which fewer than $10 \%$ of patients received transfusions [4-7]. In addition to the inherent difficulties in adequately replacing blood components in cases of severe bleeding, allogeneic blood transfusion constitutes a risk factor for intra- and postoperative morbidity, including transmission of viral disease, transfusion reactions and, in case of malignant disease, the controversial adverse effect of blood transfusion on tumor recurrence $[8,9]$.

Achieving and maintaining hemostasis is largely dependent on several key factors, including anesthetic and surgical techniques (table 1), the quality of the liver and intrinsic and extrinsic clotting components.

\section{KARGER}

Fax +41613061234 E-Mail karger@karger.ch www.karger.com
(C) 2007 S. Karger AG, Basel

0253-4886/07/0244-0288\$23.50/0

Accessible online at:

www.karger.com/dsu
Frederik Berrevoet, Department of Surgery

Division of Hepatobiliary Surgery and Liver Transplantation Service

Ghent University Hospital Medical School

2K12 IC De Pintelaan 185, BE-9000 Gent (Belgium)

Tel. +32 9240 4892, Fax +32 9240 3891, E-Mail Frederik.Berrevoet@Ugent.be 
Table 1. Anesthetic and surgical modalities to maintain peroperative hemostasis

\begin{tabular}{lll}
\hline Anesthetic & Surgical & \\
\hline Low venous pressure & Anatomical dissection & CUSA \\
Autologous transfusion & Bloodless resection & Water jet \\
Use of aprotinin & Pringle maneuver & RFA needle dissection \\
& Ischemic preconditioning & Tissue link \\
& Total vascular exclusion & Argon beam coagulation \\
& In situ hypothermic perfusion & \\
\hline
\end{tabular}

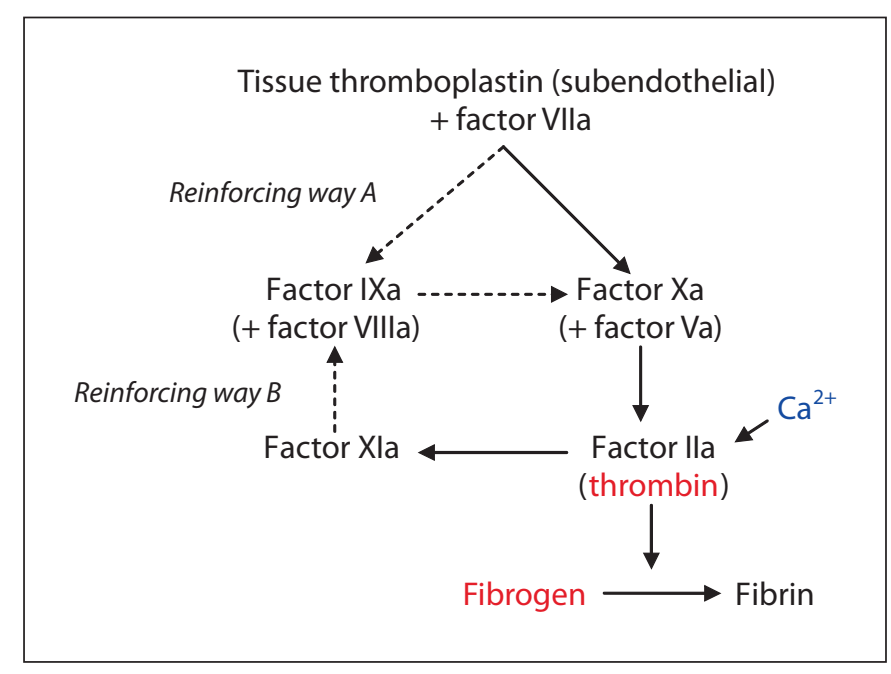

Fig. 1. Normal coagulation cascade that is mimicked by fibrin sealants.

Considering anesthesia, maintenance of low central venous pressure during liver resections is essential. This necessitates a preoperative assessment to ensure that there are no preexisting heart conditions which precludes this technique. The use of epidural anesthesia and a correct control of fluid balance during resection are also recommended.

Surgical techniques to facilitate hemostasis during liver resection have been developed during the last decades that may lead to improved outcomes. These techniques include diathermy, argon beam coagulation, hepatic inflow occlusion (Pringle maneuver, ischemic preconditioning) and total vascular exclusion [10-12]. Additional practices may include patient positioning and the use of special equipment as CUSA, harmonic scalpel, water jet and radiofrequency ablation.

The presence of parenchymal liver disease as cirrhosis or fatty infiltration makes resections more difficult. Here good surgical technique and conservative resection have become even more important and blood loss becomes a major co-factor contributing to morbidity and even mortality.

To achieve not only ultimate control of the bleeding at the resection surface but as well to prevent intraperitoneal complications attributed to bile leakage and fluid accumulation, the use of topical agents has been advocated by several groups and has now gained wide acceptance $[13,14]$. Fibrin sealants can be used for hemostasis, wound closure as well as tissue sealing and have been advocated as agents closest to approaching the ideal operative sealant [15]. Ideally, a fibrin sealant should have at least one of the following attributes: it must be effective and the product should be safe with no significant adverse effects associated with its application or its degradation products. The fibrin sealant should also be able to enhance clot formation and wound healing, and it ought to be easy to use, malleable, quickly solidifying, and reasonably priced. Fibrin sealant fulfils most of these criteria and, as such, its use has become common surgical practice across a wide range of surgical disciplines, including liver surgery.

\section{Mechanism of Action}

The real value of fibrin sealants lies in their unique physiologic action, which mimics the stages of the blood coagulation process and wound healing (fig. 1). Fibrin sealants, in contrast to the synthetic adhesives, are biocompatible. Degradation and reabsorption of the resulting fibrin clot is achieved during normal wound healing. Additionally, fibrin sealants are not associated with inflammation and tissue necrosis, unlike the cyanoacrylates and the other synthetic adhesives $[16,17]$.

Fibrin sealants are derived mainly from plasma components; most commercially available products contain purified, virally inactivated human fibrinogen and thrombin, with different quantities of factor XIII, antifibrinolytic agents (such as aprotinin) and calcium chlo- 


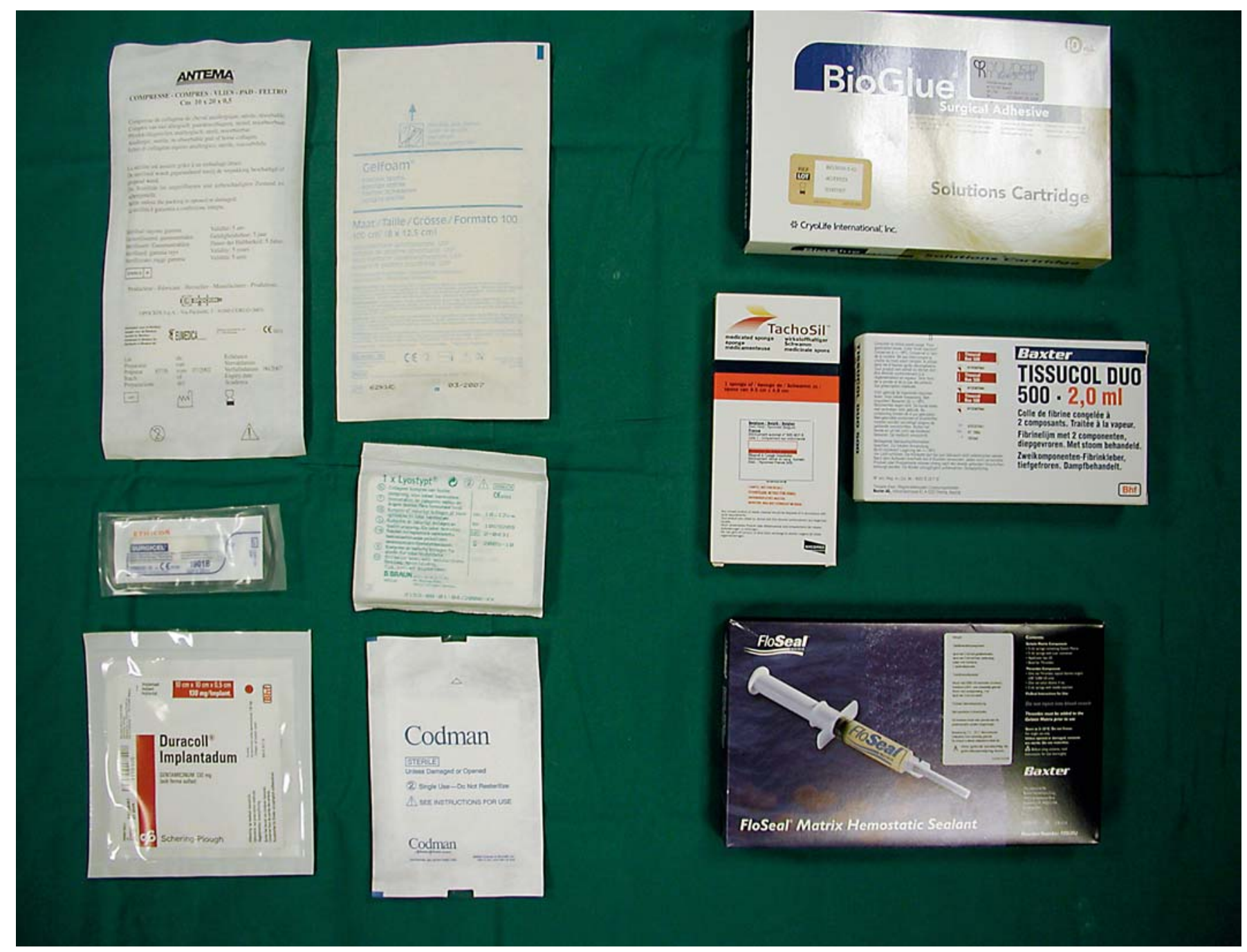

Fig. 2. Topical hemostatic agents as used in liver surgery.

ride. The sealant may be applied with a needle, as a spray or using other devices or applications. When fibrinogen and thrombin are mixed (during application of the sealant to the liver surface), the fibrinogen component is converted to fibrin monomers [18]. Polymerization of fibrin monomers results in the formation of a semirigid fibrin clot that is capable of interacting with tissue structures. These interactions are essential to stimulate adherence of fibroblasts and their normal growth into the clot, in addition to well-oriented cell growth [19]. By mimicking the later stages of the physiologic coagulation system, these processes allow fibrin sealants to arrest blood loss and assist the wound healing process. Because fibrin sealants contain naturally occurring blood components, they produce clots that are hemostatic and can be degraded by the body's own fibrinolytic mechanisms within a few weeks.

While the composition of most fibrin sealants is similar, different formulations and varying concentrations of key components, such as factor XIII, cause variation in the properties of the clots that are formed. Parameters such as speed of clot formation, adhesive strength and durability of the clot may be affected. Many factors, including the concentration of fibrinogen and thrombin, the presence of other plasma proteins, calcium concentration, ionic strength and temperature affect the rate and extent of fibrin polymerization and, ultimately, the structure of the clot [20,21]. Dickneite et al. [22] showed two components as prerequisites for successful early hemostasis, i.e. the clottable protein content and the ability 
Table 2. Tissue adhesives and fibrin sealants

\begin{tabular}{lll}
\hline Collagen fleece & Cyanoacrylate & Fibrin sealants \\
\hline Biocol & Histoacryl & Tissucol \\
Lyostipt & Tisuacryl & Tachosil \\
Antema & Glustitch & Floseal \\
Gelfoam & Dermabond & Bioglue \\
Duracol & & Beriplast \\
Lyostipt & & Quixil \\
\hline
\end{tabular}

of the application device to effectively mix the components of the sealant, particularly fibrinogen and thrombin. Delivery methods as well as the application device can alter the properties of the clot; fibrin sealants must be applied easily with thorough mixing of the components.

So far, a large number of comparable products have been released (table 2; fig. 2), but with scarce evidence of effectivity both in experimental setting and, most certainly, in clinical use. Furthermore, few comparable data are available with different commercially available fibrin sealants in terms of their ability to achieve hemostasis and to encourage wound healing.

\section{Clinical Applications}

As the ultimate goal during liver surgery is the prevention of both bleeding, fluid accumulation intraperitoneally and bile leakage, fibrin sealants have been tested in animal experiments and small clinical trials during many years with positive results most of the time [23-26]. However, only a few well-designed prospective randomized clinical trials have been documented.

Chapman et al. [27] demonstrated in their randomized controlled trial with 76 patients eligible to hepatic resection that the mixture of bovine collagen and bovine thrombin associated with autologous plasma at the time of surgery is more effectively capable of controlling and stopping diffuse hepatic bleeding than a collagen sponge alone. In a conducted trial with 121 patients the group of Schwartz [28] showed that fibrin sealants showed significantly improvement in the time to hemostasis compared to the use of standard topical hemostatic agents as Gelfoam (Pharmacia \& Upjohn, Kalamazoo, Mich., USA) or Surgicel (Ethicon, Sommerville, N.J., USA). Frilling et al. [29] showed in their randomized prospective trial that the use of hemostatic collagen fleeces was significantly more effective in terms of median time to hemostasis than was the use of argon beamer. Their significant results for time to hemostasis were supported by the results for their secondary endpoints, being the hemoglobin concentrations of the drainage fluid that proved to be significantly lower in the first postoperative days in the sealant group, even though the larger mean size of the target area in this group.

Considering all these topical agents and looking at the different trials performed, the question remains whether the use of these sealing devices is necessary to obtain optimal hemostasis and more particular to evaluate the effects on clinical benefit for the patients. Figueras et al. [30] demonstrated in a randomized trial of 300 patients undergoing different hepatic resections that the use of fibrin sealants is not justified due to a comparable complication rate considering blood transfusion, biliary fistula and overall drainage volume. However, taking this into account, $60 \%$ of all Japanese hospitals performing liver surgery feel that fibrin glue is one of the essential factors to obtain perfect hemostasis [31], even without this evidence of clinical improving the postoperative recovery. Moreover, no data are currently available considering the cost-effectiveness of these agents.

Considering the prevention of bile leakage during liver surgery using topical agents is also, or even more, controversial. The incidence of bile fistula after liver surgery at the resection site has been reported to be $5-21 \%$ [32-34], while the definition of a bile fistula may differ from 'a continuous drainage for more than 2 days with a bilirubin level over $20 \mathrm{mg} / \mathrm{dl}$ or $1,500 \mathrm{mg} /$ day' to 'drainage of bile from abdominal wound or drain with a bilirubin level of more than $5 \mathrm{mg} / \mathrm{dl}$ '. Risk factors for leakage after liver surgery include resection surface area $>60 \mathrm{~cm}^{2}$, exposure of major Glisson's sheath, S4 resection, intraoperative blood loss and preoperative chemoembolization [32, 34]. In preventing this bile leakage, peroperative treatment of the remnant liver is extremely important and infrared coagulation, argon beamer, fibrin glue or hemostatic collagen fleeces might be helpful, but meticulous preparation during resection remains the most important factor with adequate placement of clips and sutures. Recently, some reports mention the use of sealants in preventing bile leakage, mainly by application of local pressure at the resection site. Wise et al. [35] performed a randomized controlled experimental trial in which a polyethylene glycol/ collagen biopolymer sealant was tested for its usefulness to seal a standardized one-sixth circumferential anterior defect after incomplete end-to-end choledochocholedochotomy in pigs. The author concluded that the used sealant was effective in decreasing the incidence of bile leakage from $56 \%$ in the control group to $11 \%$ in the sealant 
group. Hayashibe et al. [36] published the results of a retrospective analysis of 88 patients in which they compared the use of fibrin glue in combination with bioabsorbable polyglycol acid (PGA) felt versus fibrin glue alone. They conclude again that sealing with fibrin glue and PGA felt is extremely favorable in the prevention of bile leakage. However, the only prospective randomized trial that evaluated the incidence of postoperative bile leakage observed no difference between the group treated with argon beamer and the patients treated with collagen fleeces [29]. So the question remains whether the lower incidence of leakage is really the effect of using fibrin sealants and is not e.g. the result of topical pressure at the resection site at the time of applying the sealants.

\section{Conclusion}

During extensive liver surgery, intraoperative blood loss is a major determinant in achieving favorable results. As the methods and devices used so far to achieve com- plete hemostasis after segmental liver resection failed to completely eliminate blood loss from small vascular structures and none permitted biliary and plasma leaking sites to be identified and secured without exception, there seems to be a role for fibrin sealants as an additive. Most controlled trials of fibrin glues in liver resections have however either no treatment or simple compression as comparator. The few randomized trials considering the use of sealants so far could show some benefit in obtaining hemostasis during diffuse bleeding from the parenchyma, but were unable to show any benefit in decreasing the percentage of bile fistulas. Furthermore, in no single trial has the effect on the clinical outcome been measured. So, in the absence of large prospective randomized controlled trials it still remains doubtful whether the use of fibrin sealants of other sealing devices is clinically important and cost-effective. Although it could be an additional tool, meticulous preparation during resection and thus operative skills seem at least as important and might offer, once more, a plea for centralization of this type of surgery in high-volume centers.

\section{References}

1 Holt DR, Thiel DV, Edelstein S, Brems JJ: Hepatic resections. Arch Surg 2000;135:13531358.

-2 Clark WR Jr, Leather RP: Haemostasis during liver resections. Surgery 1970;67:556557.

3 Cogbill TH, Moore EE, Jurkovich GJ, Feliciano DV, Morris JA, Mucha P: Severe hepatic trauma: a multi-center experience with 1,335 liver injuries. J Trauma 1988;28:14331438.

4 Cunningham JD, Fong Y, Shriver C, Melendez J, Marx WL, Blumgart LII: One hundred consecutive hepatic resections: blood loss, transfusion and operative technique. Arch Surg 1994;129:1050-1056.

-5 Torzilli G, Gambetti A, Del Fabbro D, Leoni P, Olivari N, Donadon M, et al: Techniques for hepatectomies without blood transfusion, focusing on interpretation of postoperative anemia. Arch Surg 2004;139:10611065.

-6 Jarnagin WR, Gonen M, Fong Y, Dematteo RP, Ben-Porat L, Little S, et al: Improvement in perioperative outcome after hepatic resection. Ann Surg 2002;236:397-407.

-7 Torzilli G, Makuuchi M, Midorikawa Y, Sano K, Inoue K, Takayama T, et al: Liver resection without total vascular exclusion: hazardous or beneficial. Ann Surg 2001;233: 167-175.
-

Kooby D, Stockman J, Ben-Porat L, Gonen M, Jarnagin WR, Dematteo RP, et al: Influence of transfusions on perioperative and long-term outcome in patients following hepatic resection for colorectal metastases. Ann Surg 2003;237:860-870.

-9 Asahara T, Katayama K, Itamoto T, Yano M, Hino $\mathrm{H}$, Okamoto $\mathrm{Y}$, et al: Perioperative blood transfusion as a prognostic indicator in patients with hepatocellular carcinoma. World J Surg 1999;23:676-680.

10 Postema RR, Plaisier PW, Kate FJ, Terpstra OT: Haemostasis after partial hepatectomy using argon beam coagulation. Br J Surg 1993;80:1563-1565.

11 Belghiti J, Noun R, Zante E, Ballet T, Sauvanet A: Portal triad clamping or hepatic vascular exclusion for major liver resection: a controlled study. Ann Surg 1996;224:155161.

12 Emre S, Schwartz ME, Katz E, Miller CM: Liver resection under total vascular isolation: variations on a theme. Ann Surg 1993; 217:15-19.

13 Belghiti J, Kabbaj M, Sauvanet A, Vilgrain V, Panis Y, Fekete F: Drainage after elective hepatic resection. A randomized trial. Ann Surg 1993;6:748-753.

14 Davidson BR, Brunnett S, Javed MS, Seifalian A, Moore D, Doctor N: Experimental study of a novel fibrin sealant for achieving haemostasis following partial hepatectomy. Br J Surg 2000;87:790-795.
15 Gibble JW, Ness PM: Fibrin glue: the perfect operative sealant? Transfusion 1990;30:741747.

16 Herod EL: Cyanoacrylates in dentistry: a review of the literature. J Can Dent Assoc 1990; 56:331-334.

17 Toriumi DM, O’Grady K: Surgical adhesives in otolaryngology-head and neck surgery. Orolaryngol Clin North Am 1994;27:203209.

18 Mosesson MW: Fibrin polymerization and its regulatory role in hemostasis. J Lab Clin Med 1990;116:8-17.

19 Kasai S, Kunimoto T, Nitta K: Cross-linking of fibrin by activated factor XIII stimulates attachment, morphological changes, and proliferation of fibroblasts. Biomed Res 1983; 4:155-160.

20 Hardy JJ, Carrell NA, McDonagh J: Calcium ion functions in fibrinogen conversion to fibrin. Ann NY Acad Sci 1983;408:279-287.

21 Okada M, Blomback B: Factors influencing fibrin gel structure studied by flow measurement. Ann NY Acad Sci 1983;408:233-253.

22 Dickneite G, Metzner H, Pfeifer T, Kroez M, Witzke G: A comparison of fibrin sealants in relation to their in vitro and in vivo properties. Thromb Res 2003;112:73-82.

23 Davidson BR, Burnett S, Javed MS, et al: Experimental study of a novel fibrin sealant for achieving haemostasis following partial hepatectomy. Br J Surg 2000;87:790-795. 
24 Turner AS, Parker D, Egbert B, et al: Evaluation of a novel hemostatic device in an ovine parenchymal organ bleeding model of normal and impaired hemostasis. J Biomed Mater Res 2002;63:37-47.

25 Lai PB, Lau WY: Icing on the cake: a modified technique to seal the raw parenchymal surface of a split liver transplantation with fibrin glue. Dig Surg 2001;18:167-168.

-26 Tokunaga Y, Tanaka K, Uemoto S, et al: Fibrin sealant of the cut surface of partial liver grafts from living donors. J Invest Surg 1995; 8:243-251.

27 Chapman WC, Clavien PA, Fung J, Khanna A, Bonham A: Effective control of hepatic bleeding with a novel collagen-based composite combined with autologous plasma. Results of a randomized controlled trial. Arch Surg 2001;135:1200-1204.
28 Schwartz M, Madariaga J, Hirose R, et al: Comparison of a new fibrin sealant with standard topical hemostatic agents. Arch Surg 2004;139:1148-1154.

-29 Frilling A, Stavrou GA, Mischinger HJ, de Hemptinne B, Rokkjær M, Klempnauer J, et al: Effectiveness of a new carrier-bound fibrin sealant versus argon beamer as haemostatic agent during liver resection: a randomized prospective trial. Langenbecks Arch Surg 2005;390:114-120.

30 Figueras J, Miro M, Llado L, et al: Application of fibrin glue sealant after hepatectomy does not seem justified. Results of a randomized study in 300 patients. HPB 2006;8(suppl 2):3-255.

31 Nakajima Y, Shimamura T, Kamiyama T, et al: Control of intraoperative bleeding during liver resection: analysis of a questionnaire sent to 231 Japanese hospitals. Surg Today 2002;32:48-52.
32 Nagano Y, Togo S, Tanaka K, et al: Risk factors and management of bile leakage after hepatic resection. World J Surg 2003;27:695698.

33 Reed DN Jr, Vitale GC, Wrightson WR, Edwards M, McMasters K: Decreasing mortality of bile leaks after elective hepatic surgery. Am J Surg 2003;185:316-318.

34 Schemmer P, Friess H, Hinz U, et al: Stapler hepatectomy is a safe dissection technique: analysis of 300 patients. World J Surg 2006; 30:419-430.

35 Wise PE, Wudel LJ, Belous AE, et al: Biliary reconstruction is enhanced with a collagenpolyethylene glycol sealant. Am Surg 2002; 68:553-562.

36 Hayashibe A, Sakamoto K, Shinbo M, Makimoto S, Nakamoto T: New method for prevention of bile leakage after hepatic resection. J Surg Oncol 2006;94:57-60. 